\title{
Extracellular Matrix Remodeling in Chronic Liver Disease
}

\author{
Cristina Ortiz $^{1} \cdot$ Robert Schierwagen $^{1} \cdot$ Liliana Schaefer $^{2} \cdot$ Sabine Klein $^{1} \cdot$ Xavier Trepat $^{3,4,5} \cdot$ Jonel Trebicka $^{1,3,6}$ (D)
}

Accepted: 9 May 2021 / Published online: 23 July 2021

(C) The Author(s) 2021

\begin{abstract}
Purpose of the Review This review aims to summarize the current knowledge of the extracellular matrix remodeling during hepatic fibrosis. We discuss the diverse interactions of the extracellular matrix with hepatic cells and the surrounding matrix in liver fibrosis, with the focus on the molecular pathways and the mechanisms that regulate extracellular matrix remodeling.

Recent Findings The extracellular matrix not only provides structure and support for the cells, but also controls cell behavior by providing adhesion signals and by acting as a reservoir of growth factors and cytokines.

Summary Hepatic fibrosis is characterized by an excessive accumulation of extracellular matrix. During fibrogenesis, the natural remodeling process of the extracellular matrix varies, resulting in the excessive accumulation of its components, mainly collagens. Signals released by the extracellular matrix induce the activation of hepatic stellate cells, which are the major source of extracellular matrix and most abundant myofibroblasts in the liver.
\end{abstract}

Keywords Liver fibrosis $\cdot$ Extracellular matrix $\cdot$ Hepatic stellate cell $\cdot$ Collagen $\cdot$ Metalloproteinases $\cdot$ TGF- $\beta 1$

\section{Introduction}

The extracellular matrix (ECM) is a complex cross-linked network of macromolecular proteins that not only provide structural support, but also play an essential role in the development and maintenance of tissue homeostasis [1]. In addition, the interaction between cells and the ECM is bi-directional. Cells are constantly receiving and accepting

This article is part of the Topical Collection on Chronic Liver Disease

Jonel Trebicka

Jonel.Trebicka@kgu.de

1 Translational Hepatology, Department of Internal Medicine I, Goethe University Frankfurt, Theodor-Stern-Kai 7, 60590 Frankfurt, Germany

2 Institute of General Pharmacology and Toxicology, University Hospital, Goethe University, Frankfurt am Main, Germany

3 Institute of Bioengineering Catalunya, Barcelona, Spain

4 Facultat de Medicina, Universitat de Barcelona, 08036 Barcelona, Spain

5 Centro de Investigación Biomédica en Red en Bioingeniería, Biomateriales y Nanomedicina (CIBER-BBN), 08028 Barcelona, Spain

6 European Foundation for Study of Chronic Liver Failure, Barcelona, Spain information from the ECM and, in turn, remodel the ECM in which old proteins are degraded and replaced by new ones in order to maintain the tissue homeostasis [2]. This interaction is mainly mediated by cell surface receptors such as integrins. Integrins are a large family of surface receptors that can signal through the cell membrane in either direction [3]. As a consequence, these integrins transmit signals that regulate cell adhesion, migration, proliferation, apoptosis, survival, or differentiation [4-6]. The ECM proteins contain sites responsible for binding to collagen, the most abundant protein and main structural element of the ECM, as well as for the cross-linking to other ECM proteins such elastin and fibronectin, allowing the degradation by proteases. The common feature of fibrotic diseases is a dysregulation of the ECM composition due to an unbalanced chronic wound-healing process, affecting its structure and biophysical properties [7, 8]. As a consequence, scar formation and tissue fibrosis develop [9].

The liver has a high regenerative potential; however, when the damage becomes persistent, this regeneration turns into chronic diseases, such as fibrosis $[10,11]$. Liver fibrosis is usually preceded by inflammation, followed by the activation of the main fibrotic cell type in the liver, the hepatic stellate cells (HSCs) [12]. It has become evident that the ECM proteins represent important mediators of the gainof-function properties of the HSC during the progression of liver fibrosis [13]. 
Progressive liver fibrosis can be caused by chronic viral hepatitis, alcohol abuse, non-alcoholic steatohepatitis (NASH), autoimmune or cholestatic disorders, and metabolic diseases $[14,15]$. Cirrhosis is the terminal stage of progressive liver fibrosis [16-18]. Hepatic fibrosis is characterized by excess accumulation of ECM [19]. Although initially beneficial, the excessive accumulation of several extracellular proteins leads to an unbalance in the wound-healing process, causing fibrosis [20]. It is important to notice that liver fibrosis is not a unidirectional process, which ultimately will lead to organ failure, but is in principle reversible [21]. In order to monitor the progression of liver fibrosis, there is a need to understand the cellular and molecular mechanisms that shift the balance from healthy to fibrotic liver and, therefore, to develop new antifibrotic therapies in the near future. In this review, we discuss the role of the ECM during liver fibrosis, including the main hepatic cell types and molecular pathways involved in this process, as well as the enzymes and ECM components that contribute and regulate the remodeling and the physical properties of ECM.

\section{Cell Types Involved in Liver Fibrosis}

Understanding liver fibrosis implies knowing how the ECM proteins change during this process, as well as how the cellular players interact with each other. The main cell types in the liver are hepatocytes, Kupffer cells, HSC, liver sinusoidal endothelial cells (LSECs), and cholangiocytes (Figure 1).

Hepatocytes are the major parenchymal cell type in the liver and account for $80-90 \%$ of the cells in the liver. As such, they perform the majority of liver functions, including nutrient metabolism and detoxification $[22,23]$. Cholangiocytes are a small epithelial cell population (3-5\%) that lines up the bile duct system [24]. Their role involves the secretion and absorption of water, electrolytes, and organic solutes [25, 26]. Kupffer cells are the resident macrophages of the liver and largest resident macrophage population in the body (80$90 \%$ ) [27, 28]. They have a high endocytic and phagocytic capacity, and they play a crucial homeostatic role in the hepatic immune system [29]. LSECs are fenestrated and form a permeable barrier between the blood and the hepatocytes and HSC which facilitates the passage of molecules from the sinusoidal endothelium to the liver parenchyma and contributes to the maintenance of the cellular and hemodynamic homeostasis [30]. HSCs are resident liver cells located in the socalled space of Disse between LSECs and hepatocytes [31••]. In the healthy liver, HSCs are present in a quiescent state, are a reservoir of retinoic acid (vitamin A), and represent approximately $10 \%$ of the liver cell population [31••, 32]. LSECs have an important role in the maintenance of the quiescent state of HSCs [33, 34]. In a healthy liver, tissue homeostasis is maintained by intracellular communication between
HSCs, hepatocytes, cholangiocytes, Kupffer cells, and LSECs, mainly via cytokines/chemokines. This mechanism is critical for maintenance of the distinct functions of the liver resident cells [35].

Liver injury disturbs tissue homeostasis and causes cell damage in hepatocytes, LSECs, and cholangiocytes leading to necrosis and the release of inflammatory markers, growth factors, reactive oxygen species, and cytokines [17, 29, 36]. Thus, tissue inflammation promotes the attraction and activation of Kupffer cells and HSCs. Although hepatocytes, Kupffer cells, LSECs, and cholangiocytes can contribute to the fibrogenic processes, the primary drivers of fibrosis are the HSCs. Activated HSCs acquire proliferative, migratory, and contractile properties and contribute to $90 \%$ of ECM while they develop a myofibroblast-like phenotype and release inflammatory molecules [37].

Portal fibroblasts are another non-parenchymal hepatic cell population and are similar to hepatic stellate cells in some characteristics, since they are also activated in chronic liver injury and contribute to ECM production in liver fibrosis. However, there are also differences between these two cell types. Portal fibroblasts play an important role in cholangitis, since they are located close to the bile ducts [38]. Hepatic stellate cells and portal fibroblasts can be differentiated by their expression profiles. While hepatic stellate cells highly express desmin and scarcely elastin, portal fibroblasts show the opposite expression pattern [39]. The differences in cell marker expression may be used for the research of portal fibroblasts, which play an inferior role in current research efforts when compared to hepatic stellate cells [38].

\section{ECM Components Implicated in Remodeling}

The ECM consists of multiple proteins, such as collagens, elastins, fibronectins, and laminins, that control the cellular phenotype and function [40]. During the transition from healthy to fibrotic liver, the homeostasis between all the ECM proteins and their specific interacting partners is shifted to cause cell inflammation and, finally, contribute to progression of liver fibrosis which in turn is associated with high morbidity and mortality [41].

There are two types of ECM [40]. The first is the basement membrane (BM) which separates the epithelium from the mesenchyme and the interstitial matrix (IM), produced by fibroblasts and surrounds cells, making up the bulk of the ECM in the body (Figure 2). Laminins, nidogen/entactin, heparan sulfate proteoglycans, and the non-fibrillar collagens, like collagen type IV, are the most abundant components of the $\mathrm{BM}$ [42]. In this regard, BM is a highly specialized type of ECM that serves as a reservoir of growth factors that direct cellular functions, provide cell adhesion, and control cell organization and differentiation [40, 43]. Types I, III, and V are 

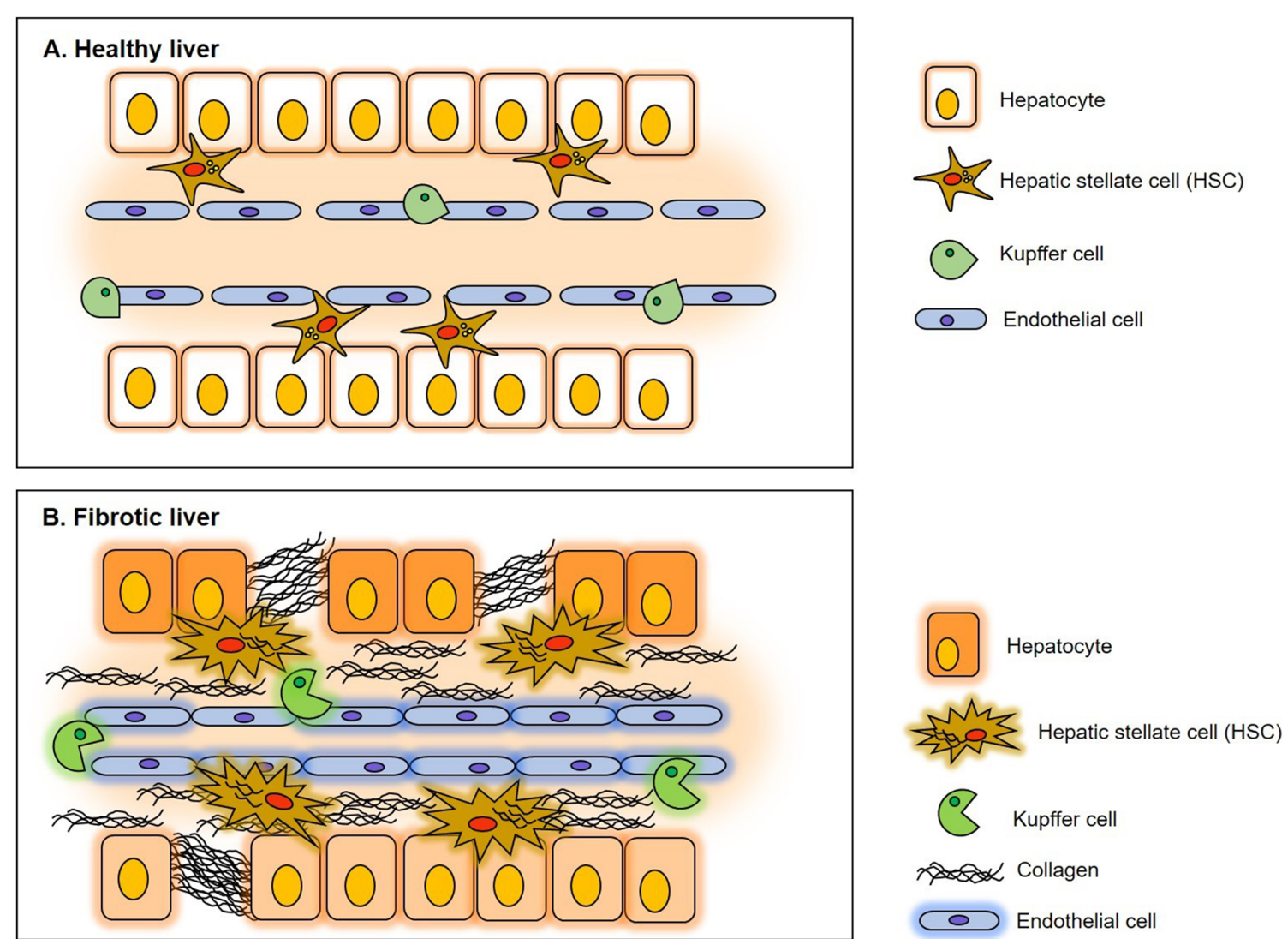

Figure 1 Cellular alterations in liver fibrosis. The main hepatic cell types in the liver are the hepatocytes, the hepatic stellate cells (HSCs), Kupffer cells, and the fenestrated endothelial cells. a In a healthy liver, the space between the hepatocytes and endothelial cells is known as the space of Disse, which are located the HSCs. b Upon injury, the HSCs become activated and secrete a large amount of extracellular matrix (ECM), which

the most abundant fibrillary collagens that form the IM, together with elastin, fibronectin, and tenascin [41, 44•]. Type I collagen is the most abundant collagen that is mainly associated with collagen III [45]. Although type V collagen is also found together with collagen I forming heterofibrils, it is not one of the major components of this complex, but it is essential for the structure of tissue [46]. This last characteristic of collagen $\mathrm{V}$ makes it unique, since it has been shown that it enhances the stability of collagen fibrils and its gene results in gradual thickening of the space. The large amount of ECM, mostly collagen, produced by the activated HSCs leads to the loss of hepatocyte and endothelial fenestrations causing an increase in the portal pressure. The imbalance caused by ECM production and the gain-function of the HSCs cause liver fibrosis.

expression is regulated by TGF- $\beta$, ending up in activation of HSCs [47].

The cross-links of the different collagens are mainly involved in the progression of liver fibrosis in the BM and the IM [48]. Due to this cross-link, an increase of up to tenfold in the collagens I, III, and V is detected [49, 50]. Type IV collagen is also increased during liver fibrogenesis, together with laminin and nidogen [51]. The collagen formation observed during fibrosis favors myofibroblast activation, and, although

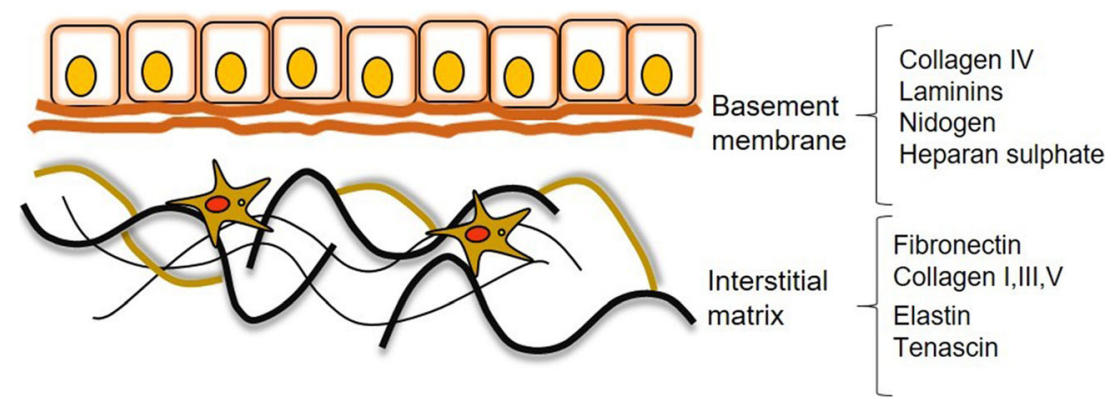

Figure 2 Schematic representation of the two types of extracellular matrix (ECM). The ECM is divided into the loose basement membrane and a compact interstitial matrix. The basement membrane consists in collagen IV, laminins, nicoden, and heparin sulfate proteoglycans. The interstitial matrix is more compact and contain the fibrillary collagens I, III, and V, elastin, fibronectin and tenascin. 
myofibroblasts are the main ECM-producers, other hepatic cell types, such hepatocytes and macrophages, are important regulators of hepatic fibrogenesis and direct effectors of fibrosis progression. The secretion of pro-fibrotic cytokines, chemokines, growth factors, or signaling peptides derived from collagens has been identified as important regulators during liver fibrosis [52].

Endostatin is a potent signaling peptide derived from the $\mathrm{C}$ terminus of collagen XVIII that is located in the BM. Collagen $\mathrm{XVIII}$ is primarily produced by hepatocytes and is associated to advanced liver fibrosis [53]. In order to reverse the fibrotic phenotype, it has been shown that endostatins ameliorate fibrosis by inhibiting HSC activation [54].

Type IV collagen fragments, from the BM, have been found to have important signaling properties [55]. Six different collagen IV chains have been described up to now $(\alpha 1-\alpha 6)$, arrestin, canstatin, tumstatin, tetrastatin, pentastatin, and hexastatin [44•, 56-60]. The first three fragments have been shown to inhibit angiogenesis in liver disease as well as endothelial cell proliferation via inhibition of MAPK pathways signaling and inducing apoptosis in endothelial cells [61]. The remaining type IV collagen chains are more limited in distribution than the first ones [51]. Tetrastatin and pentastatin possess similar anti-angiogenic activity and show inhibition of endothelial cell migration [59]; hexastatin was found to regulate endothelial cell adhesion, migration, and proliferation [62]. All together, these signaling peptides are attractive candidates for potential liver fibrosis therapy.

Restin, a signaling peptide of type XV collagen, another BM collagen, is highly abundant in the portal ECM of the liver $[63,64]$ and shows inhibitory effects on endothelial cell migration but not on their proliferation when the purified protein was assayed in vitro with different endothelial cell lines [65].

Type VI collagen is a microfibrillar collagen found between the IM and the BM that can stimulate the proliferation of mesenchymal cells $[66,67]$. During liver fibrosis, it has been found that collagen VI is up to tenfold induced in liver fibrosis [68], and its signaling peptide endotrophin plays a crucial role in fibrosis. In vivo studies showed that in $\mathrm{CCl}_{4}$-intoxicated mice, endotrophin was upregulated in injured hepatocytes contributing further to their apoptosis. The inflammatory signal released from injured hepatocytes activates HSCs, resulting in further aggravation of liver fibrosis [69, 70].

Lysyl oxidases (LOX) are the one of the family enzymes that modify the ECM [71, 72]. LOX family enzymes catalyze the cross-linking of collagens through oxidative deamination of lysine residues for the maintenance of the tensile strength and structural integrity of the ECM [73]. At least four different LOX-like (LOXL) proteins (LOXL1, LOXL2, LOXL3, and LOXL4) have been described [71]. LOXL proteins are highly controlled during normal tissue development; however, their aberrant expressions have been reported in liver disease [73]. In the liver, HSCs and portal fibroblasts are the main producers of LOX proteins [74]. During liver fibrosis specifically, LOX and LOXL2, which are absent in healthy tissues but strongly induced in liver fibrosis, have been shown to be upregulated, promoting collagen I cross-linking and its stabilization increasing its resistance to proteolytic degradation, maintaining $\mathrm{HSC}$ in an activated state [75]. Increased LOX activity has been detected in sera of patients with hepatic diseases [76, 77], suggesting the LOX family of proteins as a potential biomarker for liver fibrosis. Different approaches have been performed in order to inhibit the activity of this enzyme. For instance, inhibition of LOX with b-aminopropionitrile (BAPN), a potent inhibitor of cross-linking enzymes in the LOX family, has been shown to affect collagen cross-linking making the progression of fibrosis more reversible and delaying the effects of CCl4-intoxication [78]. In mouse models of mild liver fibrosis, it has been shown that inhibition of LOXL2 with a specific monoclonal antibody (AB0023) prevents fibrosis [79]. Further analysis using AB0023 showed efficient inhibition of collagen cross-linking, suppression of fibrosis progression $[80,81 \bullet]$.

Transglutaminases (TGs), in addition to LOX, are a wellcharacterized family of proteins that are able to covalent crosslink several collagen types from the BM and other ECM proteins like fibronectin or nicogen, increasing their resistance to proteolytic degradation, consequently losing tissue functionality [82-84]. TGs are calcium-dependent enzymes that catalyze the cross-linking, transamidation, or deamidation of proteins [85]. TG2 is the most abundant member and the most studied of the nine members of the TG family that is expressed ubiquitously in many types of tissue, cell membrane, nucleus, and extracellular [86]. During liver inflammation and fibrosis, TG2 is tightly associated with soluble integrins and fibronectins in both, covalently and non-covalently manner, promoting the fibronectin deposition into ECM, and forming stable complexes with both fibronectin and integrins [87]. This association stabilizes the integrin-ECM-fibronectin interaction, making the ECM polymers resistant to proteolytic degradation and therefore, contributing to the progression of fibrosis $[88$, 89]. In addition, it has been shown that TGF- $\beta$ enhances the binding of integrin-TG2-fibronectin in fibroblasts and elevates ECM formation during fibrosis [90]. To explore the possibility of TG2 as a target to decrease liver fibrosis, TG2 knockout mice after CCl4-induced liver damage did not show a significant decrease in liver fibrosis when compared to wildtype mice; however, these animals were more susceptible to liver inflammation, which suggest a role of TG2 in control of both inflammation and fibrosis progression [91].

\section{Molecular Signaling Pathways Involve in Liver Fibrosis}

Growth factors, such as transforming growth factor- $\beta$ (TGF- $\beta$ ), platelet-derived growth factor (PDGF) and 
connective tissue growth factor (CTGF), as well as oxidative stress are the most potent mediators of inflammatory signals to induce fibrogenesis.

The transforming growth factor- $\beta$ (TGF- $\beta$ ) signaling is known as the pathway that most hepatic cell types are susceptible to. Three TGF- $\beta$ isoforms are known in humans, two are fibrogenic, and one seems to have antagonistic properties. While TGF- $\beta 1$, the major isoform in the liver, is associated with HSC activation and ECM production in liver fibrosis in general and TGF- $\beta 2$ is associated with biliary liver disease, TGF- $\beta 3$ might inhibit TGF- $\beta 1$ and TGF- $\beta 2$ expression [92-94]. However, data on the role of TGF- $\beta 3$ in liver fibrosis is scarce.

TGF- $\beta 1$ signaling is considered one of the main pathways driving HSC activation and the most potent fibrogenic cytokine in the liver $[95,96]$. Furthermore, the correlation of TGF- $\beta 1$ with the severity of liver fibrogenesis demonstrates its importance for liver fibrosis [97]. TGF- $\beta 1$ is synthesized as a latent precursor with its prodomain and stored in the ECM as part of a large complex [98]. It is activated by mechanical force to induce the conformational changes of the latent complex and release of active TGF- $\beta$. Increased contractility by activated HSCs and increased mechanical resistance by higher liver stiffness due to accumulated ECM are the two necessary components to promote TGF- $\beta$ activation and release [99]. Integrins transmit the force of actin cytoskeleton contractility to the prodomain of the large latent TGF- $\beta$ complex in the ECM. The linkage of ECM and cytoskeleton via integrins favors the release of TGF- $\beta$ from the latent TGF- $\beta$ binding protein complex [100]. Integrins are composed of two subunits, $\alpha$ and $\beta$, and each combination has its own binding specificity and signaling properties $[95,101-103]$. Although in general the integrins $\alpha_{v} \beta 3, \alpha_{v} \beta 5, \alpha_{v} \beta 6$, and $\alpha_{v} \beta 8$ can bind this specific sequence of the latent TGF- $\beta 1$, in liver fibrosis, mainly $\alpha_{\mathrm{v}} \beta 3$ and $\alpha_{\mathrm{v}} \beta 6$ play a role [104].

While $\alpha_{v} \beta 6$ is barely expressed in normal liver, it is highly expressed in fibrosis [105]. Chemical inhibition of $\alpha_{\mathrm{v}} \beta 6$ results in downregulation of pro-fibrotic and upregulation of fibrolytic genes in experimental fibrosis [106]. Several studies have shown in vitro that cells expressing $\alpha_{v} \beta_{6}$ integrin activate TGF- $\beta 1$, and this interaction can be inhibited by blocking the integrins expressed in the myofibroblasts with antibodies, and thus reducing the fibrotic process [104]. Activated HSCs express $\alpha_{v} \beta 3$, which seems to regulate cell proliferation [107]. Pharmacological inhibition of this integrin resulted in significant collagen reduction mediated by decreased HSC activity [108].

Once activated, TGF- $\beta 1$ signals by binding to the transmembrane TGF- $\beta$ type II receptor (T $\beta$ RII), which recruits and phosphorylates TGF- $\beta$ type I receptor (T $\beta R I)$. This process transmits the extracellular TGF- $\beta 1$ signal towards the intracellular receptor part where the substrates SMAD2 and SMAD3 can bind. SMAD2/3 is activated by phosphorylation and translocates to the nucleus to regulate the transcription of genes maintaining the fibrotic and contractile state of HSCs [109]. TGF- $\beta$ activation ultimately drives fibrogenesis and ECM production. Specifically, ECM components fibronectin and collagen types I, III, and IV are regulated by TGF- $\beta 1$ signaling [97, 110]. Increased activation of HSC mediated by TGF- $\beta 1$ results in proliferation of activated cells and thereby increases the amount of contractile cells which, in turn, promote activation and release of TGF- $\beta 1$. Therefore, the interaction between HSC and TGF- $\beta 1$ in fibrogenesis can lead to a vicious cycle of a paracrine activation of HSC. The situation in portal fibroblasts is contrary to HSC. TGF- $\beta 1$ and TGF- $\beta 2$ are also produced by portal fibroblasts $[111,112]$. While TGF- $\beta 1$ and TGF- $\beta 2$ promote HSC proliferation, they inhibit proliferation of portal fibroblast. Overall, this mechanism might provide a growth advantage to HSC over portal fibroblasts [94].

The platelet-derived growth factor (PDGF) signaling pathway functions include regulation of cellular proliferation, cell migration, and stimulation of synthesis of the major components of the ECMs, such as collagen [113]. During liver fibrosis, the PDGF signaling plays an important role in activating HSCs and portal fibroblasts [114]. Among the four secreted cellular PDGF ligands, A-D, PDGF-B, and -D are the most effective in stimulating HSCs and portal myofibroblast proliferation [115]. The biological effects of PDGF are exerted through its ligands, which bind to their receptors, PDGFR- $\alpha$ and PDGFR- $\beta$, and therefore inducing proliferation, migration, and cell survival [116]. It has been shown that HSCs express both PDGF receptors; however, only $\beta$ is upregulated during its activation in vivo and in vitro specifically in liver injury [114]. In contrast to the $\beta$ isoform, the $\alpha$ isoform expression remained unchanged after liver injury. Given the importance of PDFG signaling in HSC activation during liver fibrosis, much efforts have been taken in order to pharmacologically inhibit the interaction between the ligand and the receptor [117]. There are multikinase inhibitors, sorafenib, which targets tyrosine kinase associated with PDGFR- $\beta$, showing downregulation of collagen expression in the livers of fibrotic rats $[118,119]$.

The connective tissue growth factor (CTGF) is a multifunctional protein which is highly overexpressed during liver fibrosis. CTGF regulates many cellular functions including increased cell proliferation, differentiation, migration, adhesion, and ECM synthesis, and it plays a direct role by interacting with matrix components [120, 121]. CTGF binds integrins, heparin sulfate proteoglycans, and tyrosine kinase receptors that may be located in the matrix or on the cell surface modulating signal transduction into cells $[122,123]$. CTGF is a downstream effector of TGF- $\beta$ [124], and its inhibition has been shown to suppress the TGF- $\beta$-dependent induction of ECM proteins, such as collagen and fibronectin $[125,126]$. Activated HSCs are the most important source of CTGF, although hepatocytes, portal fibroblast, and 
cholangiocytes can also contribute to its production [127, 128]. The role of CTGF in liver fibrosis has been studied in vitro using human biopsies from various chronic liver diseases, as well as in activation of HSCs, showing in both cases a strong correlation of CTGF production during liver fibrosis. These results were further confirmed in vivo in $\mathrm{CCl}_{4}$-treated and bile duct-ligated (BDL) animals to study liver fibrosis [128]. BDL is an experimental model for cholestatic liver disease which mimics the human primary biliary cirrhosis, and $\mathrm{CCl}_{4}$ induces toxic liver fibrosis [129].

Reactive oxygen species (ROS), mediating oxidative stress, are potent pro-fibrotic mediators released mostly by hepatocytes, HSCs and Kupffer cells, that stimulate the production of collagen, acting as a mediator of the fibrogenic action of TGF- $\beta[130,131]$. In liver fibrosis, NADPH oxidases (NOX) are described to be the major sources of ROS [132]. Studies have shown in vivo that NOX1, NOX2, and NOX4 are increased in two models of fibrotic mice, the BDL treatment and the $\mathrm{CCl}_{4}$ intoxication. The knockout of NOX1 and NOX4 in these animals resulted in decreased ECM synthesis and overall ROS production. As a consequence, these knockout animals showed a reduction of liver fibrosis, inflammation, and HSC proliferation [133, 134].

The renin-angiotensin system (RAS) is one of the main drivers of HSC activation [135-137, 138•]. RAS is known to be one of the most complex hormonal systems and interplay among its multiple enzymatic peptide and receptor constituents [139]. In the classical RAS, the enzyme renin cleaves its substrate angiotensinogen forming angiotensin I that is in turn, cleaved by angiotensin-converting enzyme (ACE) to produce the angiotensin II (Ang II), the biologically active peptide of the system [139]. In the classical RAS, Ang II activates the Ang II type I receptor (AT1R) to induce, among other biological processes, vasoconstriction. However, an alternative arm of the RAS cleaves Ang II by ACE homologue ACE2 to Angiotensin- [1-7] and stimulates the proto-oncogen Mas receptor cascade (MasR) causing vasodilation that generally opposes the actions of Ang II via AT1R [140, 141]. It is well-known that Ang II is the central effector that stimulates HSCs to produce pro-fibrotic cytokines, such as TGF- $\beta 1$ and CTGF, which further increases hepatic resistance to portal flow and enhanced matrix formation [138•, 142••, 143-145]. However, ACE2 is also the major cellular entry receptor for Severe Acute Respiratory Syndrome Coronavirus 2 (SARSCoV-2) as a cellular receptor to infect alveolar epithelial cells, causing the severe respiratory disease Coronavirus disease 2019 (COVID-19) in humans [146, 147].

Given the high expression of ACE2 in the liver, specifically in cholangiocytes, resident liver cells located in the bile duct, and at lower levels in hepatocytes, it has been found that a significant number of COVID-19 patients showed abnormal liver test results. Using human organoids as a tool to investigate the SARS$\mathrm{CoV}-2$ infection, it confirmed that cholangiocytes are the liver cells that express the receptor markers for being infected [148]. Downregulation of ACE2 upon binding of SARS-CoV-2 increases Ang II levels and, consequently, ECM synthesis by activated HSCs. Since SARS viruses are already known to promote pulmonary fibrosis [149], it seems very likely that the same mechanisms can lead to fibrogenesis in the liver too. In this regard, a recently published article supports this hypothesis by analysis in different infected patients and showed that the death of cholangiocytes is induced by SARS-CoV-2. As a consequence, hepatocytes release proinflammatory cytokines that can easily produce liver injury $[150,151]$.

\section{Matrix Stiffness and Inflammation}

One of the characteristic events as the liver becomes fibrotic is that the ECM stiffness increases by an extensive deposition of their extracellular proteins, including fibrillar and membrane collagens, affecting the cellular behavior [152]. The concept of stiffness has been analyzed years ago [153] and, nowadays, it is well-known that it can contribute to the mechanical properties of the ECM proteins. Matrix stiffness affects the behavior of the HSCs, including growth, motility, adhesion, and differentiation into myofibroblasts [154].

Fibrosis is associated with an increased matrix stiffness as a consequence of excessive collagen deposition and crosslinking [155]. This stiffness is detected by HSC surface receptors, the integrins, allowing the HSC activation [156]. It has been shown that the ECM components are responsible for increased matrix stiffness and, as a consequence, promotes HSC activation via cytoskeleton modulation [157॰]. An important aspect concerning matrix stiffness during liver fibrosis progression is the imbalance of the main enzymes implicated in the ECM degradation, such as the matrix metalloproteinases (MMPs) and their inhibitors. This family of proteins includes the tissue inhibitors of metalloproteinases (TIMPs) $[158,159]$. Up to now, 25 different MMPs have been identified that regulate the degradation of most ECM proteins [160]. In a normal liver, MMPs are capable to degrade any protein from the ECM in order to maintain tissue homeostasis [161]. However, when HSCs are activated and collagen accumulates excessively, the matrix regeneration fails, leading to an increase in the stiffness [162]. In this regard, in vitro studies using HSCs cultured on different substrates of varying rigidity, that mimics healthy and fibrotic liver tissue, have shown that increasing fibrotic matrix stiffness downregulates MMP-9 gene expression. As a consequence, this increase in rigidity promotes the secretion of TIMP-1 which inhibits permanently the MMP activity to degrade ECM, promoting fibrosis perpetuation [152]. In addition, other in vitro studies using activated HSCs showed that activation of the HSCs is associated as well with increased MMP-2 and MMP-14 protein expression [163]. 
Inflammation is a crucial mechanism promoting liver fibrosis by initiation of a protective response to tissue injury [ 164 , 165]. The components of the ECM are the main regulators of tissue inflammation [166]. More specifically, the ECMderived damage-associated molecular patterns (DAMPs) activate Toll-like receptors (TLRs) and the inflammasome in order to induce tissue inflammation $[167,168]$. ECM proteoglycans and their fragments, such as biglycan and decorin, are the most prominent and well-characterized ECM-derived DAMPs [169-171]. Both can interact with TLR2 and TLR4 inducing pro- and anti-inflammatory effects and recruiting macrophages $[172,173]$. Macrophages sense changes in matrix stiffness through mechanotransduction and respond by regulating the TLR-mediated inflammatory signal. In this context, the release of the proinflammatory cytokine TNF- $\alpha$, mainly involved in liver inflammation leading to fibrosis, is increased in response to TLR4 and TLR9 stimulation [174].

\section{Biophysical Mechanisms of ECM Stiffness Sensing}

ECM stiffness does not remain unrecognized by adjacent cells. It has been reported that fibroblasts tend to move from softer to stiffer regions [175]. This directed migration is called durotaxis, and the underlying mechanisms are less well-understood than in chemotaxis in which specific cell membrane receptor sense is a gradient in a soluble factor. To detect a gradient in stiffness, cells need to actively apply a pulling force to the substrate. Pulling forces are generated by the actomyosin cytoskeleton, and they can be transmitted to integrins through specific protein complexes called focal adhesions [176]. Focal adhesions contain mechanosensitive proteins such as talin and vinculin. Talin links the cytoskeleton to ECM via intregrins and vinculin shows increased binding to focal adhesion complexes with applied force. The interaction of both proteins is important to sense forces. Under force, the talin structure unfolds to expose multiple binding sites for vinculin. Without an applied force, the talin structure contains less vinculin binding site [177]. The dynamics of the linear physical connection between the actomyosin cytoskeleton and the ECM has been understood through the so-called clutch models [178]. In their simplest form, these models include the deformability of the matrix, the on and off rates of the different integrins and adaptor molecules that connect the actomyosin cytoskeleton and the ECM, and the physical relation that links force and velocity generated by myosin motors [179]. The force generated by the actomyosin cytoskeleton is contractile and results in a flow of actin towards the center of the cell, called retrograde flow. In general, this flow is inversely proportional to the traction force exerted by the cell migrating on the ECM [178].

When actomyosin-generated forces build up at focal adhesions, two main outcomes are possible depending on the rigidity of the substrate [180•]. On soft substrates, force builds up slowly and integrins unbind from the ECM before talin unfolds, resulting in rapid actin retrograde flow. By contrast, on stiff substrates force builds up fast and talin unfolds before integrins unbind, resulting in slow actin flow. Talin unfolding on stiff substrates triggers a reinforcement feedback loop by which vinculin is recruited to focal adhesions. Downstream of vinculin binding to talin, both actin and integrins are recruited to focal adhesions and mediate their reinforcement [180*]. Clutch models thus provide a conceptual framework that explains how rigidity sensing can be tuned through the regulation of vinculin and talin binding rates, activation of mechanochemical switches, and changes in cellular contractility. This mechanism has also been suggested to explain durotaxis, i.e., the ability of single cells and cell collective to migrate from soft to rigid ECM [181].

\section{Concluding Remarks}

In this review, we clearly point out the prime importance of the complex interplay between distinct cells and the ECM for health and disease in the liver, where TGF- $\beta$ occupies an outstanding position as a key mediator of this interaction. ECM not only plays an important role as the framework of the liver, but it also participates actively in the cellular processes as well as in the cellcell communication. ECM components and properties modulate physiological and pathological processes in the liver. ECM research remains a dynamic field, and recent findings might help to fight contemporary health threats like COVID-19. The complex interaction of ECM with the surrounding cells and compartments needs to be taken into account when designing diagnostic tools and therapeutical antifibrotic strategies.

Funding Open Access funding enabled and organized by Projekt DEAL.

\section{Declarations}

Conflict of Interest The authors declare no competing interests.

Human and Animal Rights and Informed Consent This article does not contain any original data on human or animal subjects performed by any of the authors, but only review of published evidence.

Open Access This article is licensed under a Creative Commons Attribution 4.0 International License, which permits use, sharing, adaptation, distribution and reproduction in any medium or format, as long as you give appropriate credit to the original author(s) and the source, provide a link to the Creative Commons licence, and indicate if changes were made. The images or other third party material in this article are included in the article's Creative Commons licence, unless indicated otherwise in a credit line to the material. If material is not included in the article's Creative Commons licence and your intended use is not permitted by statutory regulation or exceeds the permitted use, you will need to obtain permission directly from the copyright holder. To view a copy of this licence, visit http://creativecommons.org/licenses/by/4.0/. 


\section{References}

Papers of particular interest, published recently, have been highlighted as:

- Of importance

- Of major importance

1. Bedossa P, Paradis V. Liver extracellular matrix in health and disease. J Pathol. 2003;200(4):504-15.

2. Rozario T, DeSimone DW. The extracellular matrix in development and morphogenesis: a dynamic view. Dev Biol. 2010;341(1):126-40.

3. Mezu-Ndubuisi OJ, Maheshwari A. The role of integrins in inflammation and angiogenesis. Pediatr Res. 2020;7:1-8.

4. Bökel C, Brown NH. Integrins in development: moving on, responding to, and sticking to the extracellular matrix. Dev Cell. 2002;3(3):311-21.

5. Bonnans C, Chou J, Werb Z. Remodelling the extracellular matrix in development and disease. Nat Rev Mol Cell Biol. 2014;15(12):786801.

6. Harburger DS, Calderwood DA. Integrin signalling at a glance. $\mathrm{J}$ Cell Sci. 2009;122(Pt 2):159-63.

7. Rockey DC, Bell PD, Hill JA. Fibrosis-a common pathway to organ injury and failure. N Engl J Med. 2015;373(1):96.

8. Walraven M, Hinz B. Therapeutic approaches to control tissue repair and fibrosis: extracellular matrix as a game changer. Matrix Biol. 2018;71-72:205-24.

9. Harvey A, Montezano AC, Lopes RA, Rios F, Touyz RM. Vascular fibrosis in aging and hypertension: molecular mechanisms and clinical implications. Can J Cardiol. 2016;32(5):65968.

10. Cordero-Espinoza L, Huch M. The balancing act of the liver: tissue regeneration versus fibrosis. J Clin Invest. 2018 Jan 2;128(1):85-96.

11. Michalopoulos GK. Liver regeneration. J Cell Physiol. 2007;213(2):286-300.

12. Reeves HL, Friedman SL. Activation of hepatic stellate cells-a key issue in liver fibrosis. Front Biosci. 2002;7:d808-26.

13. Puche JE, Saiman Y, Friedman SL. Hepatic stellate cells and liver fibrosis. Compr Physiol. 2013;3(4):1473-92.

14. Hernandez-Gea V, Friedman SL. Pathogenesis of liver fibrosis. Annu Rev Pathol. 2011;6:425-56.

15. Wiegand J, Berg T. The etiology, diagnosis and prevention of liver cirrhosis: part 1 of a series on liver cirrhosis. Dtsch Arztebl Int. 2013;110(6):85-91.

16. Koyama Y, Brenner DA. Liver inflammation and fibrosis. J Clin Invest. 2017;127(1):55-64.

17. Pellicoro A, Ramachandran P, Iredale JP, Fallowfield JA. Liver fibrosis and repair: immune regulation of wound healing in a solid organ. Nat Rev Immunol. 2014;14(3):181-94.

18. Schuppan D, Afdhal NH. Liver cirrhosis. Lancet. 2008;371(9615):838-51.

19. Lee UE, Friedman SL. Mechanisms of hepatic fibrogenesis. Best Pract Res Clin Gastroenterol. 2011;25(2):195-206

20. Iredale JP, Thompson A, Henderson NC. Extracellular matrix degradation in liver fibrosis: biochemistry and regulation. Biochim Biophys Acta (BBA) - Mol Basis Dis. 2013;1832(7): 876-83.

21. Iredale JP, Benyon RC, Pickering J, McCullen M, Northrop M, Pawley S, et al. Mechanisms of spontaneous resolution of rat liver fibrosis. Hepatic stellate cell apoptosis and reduced hepatic expression of metalloproteinase inhibitors. J Clin Invest. 1998;102(3):538-49.
22. Schulze RJ, Schott MB, Casey CA, Tuma PL, McNiven MA. The cell biology of the hepatocyte: a membrane trafficking machine. J Cell Biol. 2019;218(7):2096-112.

23. Treyer A, Müsch A. Hepatocyte polarity. Compr Physiol. 2013;3(1):243-87.

24. LeSage G, Glaser S, Alpini G. Regulation of cholangiocyte proliferation. Liver. 2001;21(2):73-80.

25. Banales JM, Huebert RC, Karlsen T, Strazzabosco M, LaRusso NF, Gores GJ. Cholangiocyte pathobiology. Nat Rev Gastroenterol Hepatol. 2019;16(5):269-81.

26. Tam PKH, Yiu RS, Lendahl U, Andersson ER. Cholangiopathies - Towards a molecular understanding. EBioMedicine. 2018;35: 381-93.

27. Blériot C, Ginhoux F. Understanding the heterogeneity of resident liver macrophages. Front Immunol. 2019;10:2694.

28. Dixon LJ, Barnes M, Tang H, Pritchard MT, Nagy LE. Kupffer cells in the liver. Compr Physiol. 2013;3(2):785-97.

29. Vollmar B, Menger MD. The hepatic microcirculation: mechanistic contributions and therapeutic targets in liver injury and repair. Physiol Rev. 2009;89(4):1269-339.

30. Rockey D. The cellular pathogenesis of portal hypertension: stellate cell contractility, endothelin, and nitric oxide. Hepatology. 1997;25(1):2-5.

31.• Friedman SL. Hepatic stellate cells: protean, multifunctional, and enigmatic cells of the liver. Physiol Rev. 2008;88(1):125-72 This review reflects and summarizes the current knowledge about molecular insights in hepatic stellate cell biology.

32. Wake K. 'Sternzellen' in the liver: perisinusoidal cells with special reference to storage of vitamin A. Am J Anat. 1971 Dec;132(4): 429-62.

33. Shetty S, Lalor PF, Adams DH. Liver sinusoidal endothelial cells gatekeepers of hepatic immunity. Nat Rev Gastroenterol Hepatol. 2018;15(9):555-67.

34. Sørensen KK, Simon-Santamaria J, McCuskey RS, Smedsrød B. Liver sinusoidal endothelial cells. Compr Physiol. 2015 Sep 20;5(4):1751-74.

35. Heymann F, Tacke F. Immunology in the liver-from homeostasis to disease. Nat Rev Gastroenterol Hepatol. 2016 Feb;13(2):88 110.

36. Jenne $\mathrm{CN}$, Kubes P. Immune surveillance by the liver. Nat Immunol. 2013 Oct;14(10):996-1006.

37. Mederacke I, Hsu CC, Troeger JS, Huebener P, Mu X, Dapito $\mathrm{DH}$, et al. Fate tracing reveals hepatic stellate cells as dominant contributors to liver fibrosis independent of its aetiology. Nat Commun. 2013;4:2823.

38. Dranoff JA, Wells RG. Portal fibroblasts: underappreciated mediators of biliary fibrosis. Hepatology. 2010 Apr;51(4):1438-44.

39. Li Z, Dranoff JA, Chan EP, Uemura M, Sévigny J, Wells RG. Transforming growth factor- $\beta$ and substrate stiffness regulate portal fibroblast activation in culture. Hepatology. 2007;46(4):1246-56.

40. Karsdal MA, Nielsen MJ, Sand JM, Henriksen K, Genovese F, Bay-Jensen A-C, et al. Extracellular matrix remodeling: the common denominator in connective tissue diseases. Possibilities for evaluation and current understanding of the matrix as more than a passive architecture, but a key player in tissue failure. Assay Drug Dev Technol. 2013 Mar;11(2):70-92.

41. Karsdal MA, Manon-Jensen T, Genovese F, Kristensen JH, Nielsen MJ, Sand JMB, et al. Novel insights into the function and dynamics of extracellular matrix in liver fibrosis. Am J Physiol Gastrointest Liver Physiol. 2015 May 15;308(10): G807-30.

42. Pozzi A, Yurchenco PD, Iozzo RV. The nature and biology of basement membranes. Matrix Biol. 2017;57-58:1-11.

43. Yurchenco PD. Basement membranes: cell scaffoldings and signaling platforms. Cold Spring Harb Perspect Biol. 2011 Feb;1: $3(2)$. 
44•. . Karsdal MA, Nielsen SH, Leeming DJ, Langholm LL, Nielsen MJ, Manon-Jensen T, et al. The good and the bad collagens of fibrosis - their role in signaling and organ function. Adv Drug Deliv Rev. 2017;121:43-56 This review provides an overview of the collagen types in the ECM and their molecular role in fibrosis.

45. Hinz B, Phan SH, Thannickal VJ, Galli A, Bochaton-Piallat M-L, Gabbiani G. The myofibroblast: one function, multiple origins. Am J Pathol. 2007;170(6):1807-16.

46. Gelse K, Pöschl E, Aigner T. Collagens-structure, function, and biosynthesis. Adv Drug Deliv Rev. 2003;55(12):1531-46.

47. Mak KM, Png CYM, Lee DJ. Type V collagen in health, disease, and fibrosis. Anat Rec (Hoboken). 2016;299(5):613-29.

48. Brown B, Lindberg K, Reing J, Stolz DB, Badylak SF. The basement membrane component of biologic scaffolds derived from extracellular matrix. Tissue Eng. 2006;12(3):519-26.

49. MacKenna D, Summerour SR, Villarreal FJ. Role of mechanical factors in modulating cardiac fibroblast function and extracellular matrix synthesis. Cardiovasc Res. 2000;46(2):257-63.

50. Rojkind M, Giambrone MA, Biempica L. Collagen types in normal and cirrhotic liver. Gastroenterology. 1979;76(4):710-9.

51. Hudson BG, Tryggvason K, Sundaramoorthy M, Neilson EG. Alport's syndrome, Goodpasture's syndrome, and type IV collagen. N Engl J Med. 2003;348(25):2543-56.

52. Wynn TA. Cellular and molecular mechanisms of fibrosis. J Pathol. 2008;214(2):199-210.

53. Schuppan D, Cramer T, Bauer M, Strefeld T, Hahn EG, Herbst H. Hepatocytes as a source of collagen type XVIII endostatin. Lancet. 1998;352(9131):879-80.

54. Ren H, Li Y, Chen Y, Wang L. Endostatin attenuates PDGF-BBor TGF- $\beta 1$-induced HSCs activation via suppressing RhoA/ROCK1 signal pathways. Drug Des Devel Ther. 2019;13: 285-90.

55. Zhou J, Ding M, Zhao Z, Reeders ST. Complete primary structure of the sixth chain of human basement membrane collagen, alpha 6(IV). Isolation of the cDNAs for alpha 6(IV) and comparison with five other type IV collagen chains. J Biol Chem. 1994:269(18):13193-9.

56. Kamphaus GD, Colorado PC, Panka DJ, Hopfer H, Ramchandran $\mathrm{R}$, Torre A, et al. Canstatin, a novel matrix-derived inhibitor of angiogenesis and tumor growth. J Biol Chem. 2000;275(2):120915.

57. Hamano Y, Zeisberg M, Sugimoto H, Lively JC, Maeshima Y, Yang C, et al. Physiological levels of tumstatin, a fragment of collagen IV alpha3 chain, are generated by MMP-9 proteolysis and suppress angiogenesis via alphaV beta3 integrin. Cancer Cell. 2003;3(6):589-601.

58. Colorado PC, Torre A, Kamphaus G, Maeshima Y, Hopfer H, Takahashi K, et al. Anti-angiogenic cues from vascular basement membrane collagen. Cancer Res. 2000;60(9):2520-6.

59. Karagiannis ED, Popel AS. Identification of novel short peptides derived from the alpha 4, alpha 5, and alpha 6 fibrils of type IV collagen with anti-angiogenic properties. Biochem Biophys Res Commun. 2007;354(2):434-9.

60. Mundel TM, Kalluri R. Type IV collagen-derived angiogenesis inhibitors. Microvasc Res. 2007;74(2-3):85-9.

61. Cooke VG, Kalluri R. Chapter 1. Molecular mechanism of type IV collagen-derived endogenous inhibitors of angiogenesis. Methods Enzymol. 2008;444:1-19.

62. Sund M, Nyberg P, Eikesdal HP. Endogenous matrix-derived inhibitors of angiogenesis. Pharmaceuticals (Basel). 2010;3(10): 3021-39.

63. Hägg PM, Hägg PO, Peltonen S, Autio-Harmainen H, Pihlajaniemi T. Location of type XV collagen in human tissues and its accumulation in the interstitial matrix of the fibrotic kidney. Am J Pathol. 1997;150(6):2075-86.
64. Harrison SA, Rossi SJ, Paredes AH, Trotter JF, Bashir MR, Guy CD, et al. NGM282 improves liver fibrosis and histology in 12 weeks in patients with nonalcoholic steatohepatitis. Hepatology. 2020;71(4):1198-212.

65. Ramchandran R, Dhanabal M, Volk R, Waterman MJ, Segal M, $\mathrm{Lu} \mathrm{H}$, et al. Antiangiogenic activity of restin, $\mathrm{NC10}$ domain of human collagen XV: comparison to endostatin. Biochem Biophys Res Commun. 1999;255(3):735-9.

66. Atkinson JC, Rühl M, Becker J, Ackermann R, Schuppan D. Collagen VI regulates normal and transformed mesenchymal cell proliferation in vitro. Exp Cell Res. 1996;228(2):283-91.

67. Villesen IF, Daniels SJ, Leeming DJ, Karsdal MA, Nielsen MJ. Review article: the signalling and functional role of the extracellular matrix in the development of liver fibrosis. Aliment Pharmacol Ther. 2020;52(1):85-97.

68. Schuppan D, Rühlmann T, Hahn EG. Radioimmunoassay for human type VI collagen and its application to tissue and body fluids. Anal Biochem. 1985;149(1):238-47.

69. Karsdal M, Reese-Petersen A, Nielsen MJ, Krag A, Thiele M, Gudmann N, et al. The pro-peptide of type VI collagen (endotrophin) is equipotent to Tgf-B in inducing fibrosis: identification of a self-perpetuating vicious cycle driving fibrosis mediated by collagen signals. In: Hepatology [Internet]. JohnWiley \& Sons, Inc.; 2019;84A-85A. Availablefrom: https://portal. findresearcher.sdu.dk/en/publications/the-pro-peptide-of-type-vicollagen-endotrophin-is-equipotent-to-. Accessed 16 Dec 2020.

70. Lee C, Kim M, Lee JH, Oh J, Shin H-H, Lee SM, et al. COL6A3derived endotrophin links reciprocal interactions among hepatic cells in the pathology of chronic liver disease. J Pathol. 2019;247(1):99-109.

71. Csiszar K. Lysyl oxidases: a novel multifunctional amine oxidase family. Prog Nucleic Acid Res Mol Biol. 2001;70:1-32.

72. Lucero HA, Kagan HM. Lysyl oxidase: an oxidative enzyme and effector of cell function. Cell Mol Life Sci. 2006;63(19-20):2304 16.

73. Kagan HM. Lysyl oxidase: mechanism, regulation and relationship to liver fibrosis. Pathol Res Pract. 1994;190(9-10):910-9.

74. Perepelyuk M, Terajima M, Wang AY, Georges PC, Janmey PA, Yamauchi M, et al. Hepatic stellate cells and portal fibroblasts are the major cellular sources of collagens and lysyl oxidases in normal liver and early after injury. Am J Physiol Gastrointest Liver Physiol. 2013;304(6):G605-14.

75. Kagan HM, Li W. Lysyl oxidase: properties, specificity, and biological roles inside and outside of the cell. J Cell Biochem. 2003;88(4):660-72.

76. Mesarwi OA, Shin M-K, Drager LF, Bevans-Fonti S, Jun JC, Putcha N, et al. Lysyl oxidase as a serum biomarker of liver fibrosis in patients with severe obesity and obstructive sleep apnea. Sleep. 2015;38(10):1583-91.

77. Murawaki Y, Kusakabe Y, Hirayama C. Serum lysyl oxidase activity in chronic liver disease in comparison with serum levels of prolyl hydroxylase and laminin. Hepatology. 1991;14(6):116773.

78. Liu SB, Ikenaga N, Peng Z-W, Sverdlov DY, Greenstein A, Smith $\mathrm{V}$, et al. Lysyl oxidase activity contributes to collagen stabilization during liver fibrosis progression and limits spontaneous fibrosis reversal in mice. FASEB J. 2016;30(4):1599-609.

79. Barry-Hamilton V, Spangler R, Marshall D, McCauley S, Rodriguez HM, Oyasu M, et al. Allosteric inhibition of lysyl oxidase-like-2 impedes the development of a pathologic microenvironment. Nat Med. 2010;16(9):1009-17.

80. Ikenaga N, Peng Z-W, Vaid KA, Liu SB, Yoshida S, Sverdlov DY, et al. Selective targeting of lysyl oxidase-like 2 (LOXL2) suppresses hepatic fibrosis progression and accelerates its reversal. Gut. 2017;66(9):1697-708. 
81. Magdaleno F, Schierwagen R, Uschner FE, Trebicka J. 'Tipping' extracellular matrix remodeling towards regression of liver fibrosis: novel concepts. Minerva Gastroenterol Dietol. 2018;64(1): 51-61 This review outlines important mechanisms leading towards liver fibrosis regression.

82. Brown-Augsburger P, Broekelmann T, Mecham L, Mercer R, Gibson MA, Cleary EG, et al. Microfibril-associated glycoprotein binds to the carboxyl-terminal domain of tropoelastin and is a substrate for transglutaminase. J Biol Chem. 1994;269(45): 28443-9.

83. Aeschlimann D, Paulsson M. Transglutaminases: protein crosslinking enzymes in tissues and body fluids. Thromb Haemost. 1994;71(4):402-15.

84. Kadler KE, Hill A, Canty-Laird EG. Collagen fibrillogenesis: fibronectin, integrins, and minor collagens as organizers and nucleators. Curr Opin Cell Biol. 2008;20(5):495-501.

85. Griffin M, Casadio R, Bergamini CM. Transglutaminases: nature's biological glues. Biochem J. 2002;368(Pt 2):377-96.

86. Odii BO, Coussons P. Biological functionalities of transglutaminase 2 and the possibility of its compensation by other members of the transglutaminase family. ScientificWorldJournal [Internet]. 2014 Mar 23. Available from: https://www.ncbi.nlm.nih.gov/pmc/articles/PMC3981525/. Accessed 25 Nov 2020.

87. Belkin AM. Extracellular TG2: emerging functions and regulation. FEBS J. 2011;278(24):4704-16.

88. Lorand L, Graham RM. Transglutaminases: crosslinking enzymes with pleiotropic functions. Nat Rev Mol Cell Biol. 2003;4(2):140 56.

89. Zemskov EA, Janiak A, Hang J, Waghray A, Belkin AM. The role of tissue transglutaminase in cell-matrix interactions. Front Biosci. 2006; 11:1057-76.

90. Elli L, Bergamini CM, Bardella MT, Schuppan D. Transglutaminases in inflammation and fibrosis of the gastrointestinal tract and the liver. Dig Liver Dis. 2009;41(8):541-50.

91. Popov Y, Sverdlov DY, Sharma AK, Bhaskar KR, Li S, Freitag $\mathrm{TL}$, et al. Tissue transglutaminase does not affect fibrotic matrix stability or regression of liver fibrosis in mice. Gastroenterology. 2011;140(5):1642-52

92. Wang L, Tu L, Zhang J, Xu K, Qian W. Stellate cell activation and imbalanced expression of TGF- $\beta 1 /$ TGF- $\beta 3$ in acute autoimmune liver lesions induced by ConA in mice. Biomed Res Int [Internet]. 2017. Available from: https://www.ncbi.nlm.nih.gov/pmc/ articles/PMC5303577/. Accessed 24 Mar 2021.

93. Fabregat I, Moreno-Càceres J, Sánchez A, Dooley S, Dewidar B, Giannelli $G$, et al. TGF- $\beta$ signalling and liver disease. FEBS J. 2016;283(12):2219-32.

94. Wells RG, Kruglov E, Dranoff JA. Autocrine release of TGF-beta by portal fibroblasts regulates cell growth. FEBS Lett. 2004;559(1-3):107-10.

95. Dewidar B, Meyer C, Dooley S, Meindl-Beinker AN. TGF- $\beta$ in hepatic stellate cell activation and liver fibrogenesis-updated Cells. 2019 Nov 11;8(11):1419.

96. Inagaki Y, Okazaki I. Emerging insights into transforming growth factor beta Smad signal in hepatic fibrogenesis. Gut. 2007;56(2): 284-92.

97. Kanzler S, Lohse AW, Keil A, Henninger J, Dienes HP, Schirmacher P, et al. TGF-betal in liver fibrosis: an inducible transgenic mouse model to study liver fibrogenesis. Am J Phys. 1999;276(4):G1059-68.

98. Shi M, Zhu J, Wang R, Chen X, Mi L, Walz T, et al. Latent TGF- $\beta$ structure and activation. Nature. 2011;474(7351):343-9.

99. Hinz B. The extracellular matrix and transforming growth factor$\beta 1$ : tale of a strained relationship. Matrix Biol. 2015;47:54-65.

100. Conroy KP, Kitto LJ, Henderson NC. $\alpha$ v integrins: key regulators of tissue fibrosis. Cell Tissue Res. 2016;365(3):511-9.
101. Fan W, Liu T, Chen W, Hammad S, Longerich T, Hausser I, et al. ECM1 prevents activation of transforming growth factor $\beta$, hepatic stellate cells, and fibrogenesis in mice. Gastroenterology. 2019;157(5):1352-1367.e13.

102. Nishimura SL. Integrin-mediated transforming growth factor-beta activation, a potential therapeutic target in fibrogenic disorders. Am J Pathol. 2009;175(4):1362-70.

103. Giancotti FG, Ruoslahti E. Integrin signaling. Science. 1999;285(5430):1028-32.

104. Henderson NC, Sheppard D. Integrin-mediated regulation of TGF $\beta$ in fibrosis. Biochim Biophys Acta (BBA) - Mol Basis Dis. 2013;1832(7):891-6.

105. Popov Y, Patsenker E, Stickel F, Zaks J, Bhaskar KR, Niedobitek $\mathrm{G}$, et al. Integrin alphavbeta6 is a marker of the progression of biliary and portal liver fibrosis and a novel target for antifibrotic therapies. J Hepatol. 2008;48(3):453-64.

106. Patsenker E, Popov Y, Stickel F, Jonczyk A, Goodman SL, Schuppan D. Inhibition of integrin alphavbeta6 on cholangiocytes blocks transforming growth factor-beta activation and retards biliary fibrosis progression. Gastroenterology. 2008;135(2):660-70.

107. Zhou X, Murphy FR, Gehdu N, Zhang J, Iredale JP, Benyon RC. Engagement of alphavbeta3 integrin regulates proliferation and apoptosis of hepatic stellate cells. J Biol Chem. 2004;279(23): 23996-4006.

108. Patsenker E, Popov Y, Stickel F, Schneider V, Ledermann M, Sägesser H, et al. Pharmacological inhibition of integrin alphavbeta3 aggravates experimental liver fibrosis and suppresses hepatic angiogenesis. Hepatology. 2009;50(5):1501-11.

109. Derynck R, Budi EH. Specificity, versatility, and control of TGF$\beta$ family signaling. Sci Signal. 2019 Feb26;12(570):eaav5183.

110. Knittel T, Janneck T, Müller L, Fellmer P, Ramadori G. Transforming growth factor beta 1-regulated gene expression of Ito cells. Hepatology. 1996;24(2):352-60.

111. Liu C, Gaça MDA, Swenson ES, Vellucci VF, Reiss M, Wells RG. Smads 2 and 3 are differentially activated by transforming growth factor-beta (TGF-beta) in quiescent and activated hepatic stellate cells. Constitutive nuclear localization of Smads in activated cells is TGF-beta-independent. J Biol Chem. 2003;278(13): 11721-8.

112. Milani S, Herbst H, Schuppan D, Stein H, Surrenti C. Transforming growth factors beta 1 and beta 2 are differentially expressed in fibrotic liver disease. Am J Pathol. 1991;139(6): 1221-9.

113. Heldin C-H, Westermark B. Mechanism of action and in vivo role of platelet-derived growth factor. Physiol Rev. 1999;79(4):1283316.

114. Wong L, Yamasaki G, Johnson RJ, Friedman SL. Induction of beta-platelet-derived growth factor receptor in rat hepatic lipocytes during cellular activation in vivo and in culture. J Clin Invest. 1994;94(4):1563-9.

115. Ying H-Z, Chen Q, Zhang W-Y, Zhang H-H, Ma Y, Zhang S-Z, et al. PDGF signaling pathway in hepatic fibrosis pathogenesis and therapeutics. Mol Med Rep. 2017;16(6):7879-89.

116. Kelly JD, Haldeman BA, Grant FJ, Murray MJ, Seifert RA, Bowen-Pope DF, et al. Platelet-derived growth factor (PDGF) stimulates PDGF receptor subunit dimerization and intersubunit trans-phosphorylation. J Biol Chem. 1991;266(14):8987-92.

117. Borkham-Kamphorst E, Stoll D, Gressner AM, Weiskirchen R. Antisense strategy against PDGF B-chain proves effective in preventing experimental liver fibrogenesis. Biochem Biophys Res Commun. 2004;321(2):413-23.

118. Ogawa S, Ochi T, Shimada H, Inagaki K, Fujita I, Nii A, et al. Anti-PDGF-B monoclonal antibody reduces liver fibrosis development. Hepatol Res. 2010;40(11):1128-41. 
119. Wang Y, Gao J, Zhang D, Zhang J, Ma J, Jiang H. New insights into the antifibrotic effects of sorafenib on hepatic stellate cells and liver fibrosis. J Hepatol. 2010;53(1):132-44.

120. Rachfal AW, Brigstock DR. Connective tissue growth factor (CTGF/CCN2) in hepatic fibrosis. Hepatol Res. 2003;26(1):1-9.

121. Yoshida K, Munakata H. Connective tissue growth factor binds to fibronectin through the type I repeat modules and enhances the affinity of fibronectin to fibrin. Biochim Biophys Acta Gen Subj. 2007;1770(4):672-80.

122. Jun J-I, Lau LF. Taking aim at the extracellular matrix: CCN proteins as emerging therapeutic targets. Nat Rev Drug Discov. 2011;10(12):945-63.

123. Gao R, Brigstock DR. Connective tissue growth factor (CCN2) induces adhesion of rat activated hepatic stellate cells by binding of its C-terminal domain to integrin alpha(v)beta(3) and heparan sulfate proteoglycan. J Biol Chem. 2004;279(10):8848-55.

124. Igarashi A, Okochi H, Bradham DM, Grotendorst GR. Regulation of connective tissue growth factor gene expression in human skin fibroblasts and during wound repair. Mol Biol Cell. 1993;4(6): $637-45$.

125. Kothapalli D, Frazier KS, Welply A, Segarini PR, Grotendorst GR. Transforming growth factor beta induces anchorageindependent growth of NRK fibroblasts via a connective tissue growth factor-dependent signaling pathway. Cell Growth Differ. 1997;8(1):61-8.

126. Duncan MR, Frazier KS, Abramson S, Williams S, Klapper H, Huang X, et al. Connective tissue growth factor mediates transforming growth factor beta-induced collagen synthesis: down-regulation by cAMP. FASEB J. 1999;13(13):1774-86.

127. Abou-Shady M, Friess H, Zimmermann A, di Mola FF, Guo XZ, Baer HU, et al. Connective tissue growth factor in human liver cirrhosis. Liver. 2000;20(4):296-304.

128. Paradis V, Dargere D, Vidaud M, De Gouville AC, Huet S, Martinez V, et al. Expression of connective tissue growth factor in experimental rat and human liver fibrosis. Hepatology. 1999;30(4):968-76.

129. Klein S, Schierwagen R, Uschner FE, Trebicka J. Mouse and rat models of induction of hepatic fibrosis and assessment of portal hypertension. Methods Mol Biol. 1627;2017:91-116.

130. Luedde T, Kaplowitz N, Schwabe RF. Cell death and cell death responses in liver disease: mechanisms and clinical relevance. Gastroenterology. 2014;147(4):765-783.e4.

131. Tsuchida T, Friedman SL. Mechanisms of hepatic stellate cell activation. Nat Rev Gastroenterol Hepatol. 2017;14(7):397-411.

132. Liang S, Kisseleva T, Brenner DA. The role of NADPH oxidases (NOXs) in liver fibrosis and the activation of myofibroblasts. Front Physiol [Internet]. 2016 Feb 2;7:17. Available from: https://www.ncbi.nlm.nih.gov/pmc/articles/PMC4735448/. Accessed 20 Nov 2020.

133. Lan T, Kisseleva T, Brenner DA. Deficiency of NOX1 or NOX4 prevents liver inflammation and fibrosis in mice through inhibition of hepatic stellate cell activation. PLoS One. 2015;10(7): e0129743.

134. Paik Y-H, Iwaisako K, Seki E, Inokuchi S, Schnabl B, Österreicher $\mathrm{CH}$, et al. The nicotinamide adenine dinucleotide phosphate oxidase homologues NOX1 and NOX2/gp91phox mediate hepatic fibrosis in mice. Hepatology. 2011;53(5):1730-41.

135. Bataller R, Ginès P, Nicolás JM, Görbig MN, Garcia-Ramallo E, Gasull X, et al. Angiotensin II induces contraction and proliferation of human hepatic stellate cells. Gastroenterology. 2000;118(6):1149-56.

136. Heller J, Shiozawa T, Trebicka J, Hennenberg M, Schepke M, Neef M, et al. Acute haemodynamic effects of losartan in anaesthetized cirrhotic rats. Eur J Clin Investig. 2003;33(11):1006-12.

137. Heller J, Trebicka J, Shiozawa T, Schepke M, Neef M, Hennenberg M, et al. Vascular, hemodynamic and renal effects of low-dose losartan in rats with secondary biliary cirrhosis. Liver Int. 2005;25(3):657-66.

138•. Granzow M, Schierwagen R, Klein S, Kowallick B, Huss S, Linhart M, et al. Angiotensin-II type 1 receptor-mediated Janus kinase 2 activation induces liver fibrosis. Hepatology. 2014;60(1):334-48 This study describes the role of JAK2 in HSCs as an effector of AT1R in liver fibrosis.

139. Carey RM. Newly discovered components and actions of the renin-angiotensin system. Hypertension. 2013;62(5):818-22.

140. Tipnis SR, Hooper NM, Hyde R, Karran E, Christie G, Turner AJ. A human homolog of angiotensin-converting enzyme. Cloning and functional expression as a captopril-insensitive carboxypeptidase. J Biol Chem. 2000;275(43):33238-43.

141. Donoghue M, Hsieh F, Baronas E, Godbout K, Gosselin M, Stagliano N, et al. A novel angiotensin-converting enzyme-related carboxypeptidase (ACE2) converts angiotensin I to angiotensin 19. Circ Res. 2000;87(5):E1-9.

142.• Klein S, Rick J, Lehmann J, Schierwagen R, Schierwagen IG, Verbeke L, et al. Janus-kinase-2 relates directly to portal hypertension and to complications in rodent and human cirrhosis. Gut. 2017;66(1):145-55 This study describes de inhibition of Jak2 as a potential target to treat liver cirrhosis with portal hypertension.

143. Bataller R, Gäbele E, Schoonhoven R, Morris T, Lehnert M, Yang $\mathrm{L}$, et al. Prolonged infusion of angiotensin II into normal rats induces stellate cell activation and proinflammatory events in liver. Am J Physiol Gastrointest Liver Physiol. 2003;285(3):G64251.

144. Bataller R, Sancho-Bru P, Ginès P, Lora JM, Al-Garawi A, Solé $\mathrm{M}$, et al. Activated human hepatic stellate cells express the reninangiotensin system and synthesize angiotensin II. Gastroenterology. 2003;125(1):117-25.

145. Paizis G, Cooper ME, Schembri JM, Tikellis C, Burrell LM, Angus PW. Up-regulation of components of the reninangiotensin system in the bile duct-ligated rat liver. Gastroenterology. 2002;123(5):1667-76.

146. Warner FJ, Rajapaksha H, Shackel N, Herath CB. ACE2: from protection of liver disease to propagation of COVID-19. Clin Sci (Lond). 2020;134(23):3137-58.

147. Hoffmann M, Kleine-Weber H, Schroeder S, Krüger N, Herrler T, Erichsen S, et al. SARS-CoV-2 cell entry depends on ACE2 and TMPRSS 2 and is blocked by a clinically proven protease inhibitor. Cell. 2020;181(2):271-280.e8.

148. Zhao B, Ni C, Gao R, Wang Y, Yang L, Wei J, et al. Recapitulation of SARS-CoV-2 infection and cholangiocyte damage with human liver ductal organoids. Protein Cell. 2020;11(10):771-5.

149. Wigén J, Löfdahl A, Bjermer L, Elowsson-Rendin L, WestergrenThorsson G. Converging pathways in pulmonary fibrosis and Covid-19 - the fibrotic link to disease severity. Respir Med X. 2020;2:100023.

150. Lopez-Mendez I, Aquino-Matus J, Gall SM-B, Prieto-Nava JD, Juarez-Hernandez E, Uribe M, et al. Association of liver steatosis and fibrosis with clinical outcomes in patients with SARS-CoV-2 infection (COVID-19). Ann Hepatol. 2020;20:100271.

151. Saviano A, Wrensch F, Ghany MG, Baumert TF. Liver disease and COVID-19: from pathogenesis to clinical care. Hepatology. https://doi.org/10.1002/hep.31684.

152. Lachowski D, Cortes E, Rice A, Pinato D, Rombouts K, del Rio Hernandez A. Matrix stiffness modulates the activity of MMP-9 and TIMP-1 in hepatic stellate cells to perpetuate fibrosis. Sci Rep. 2019;9(1):7299.

153. Carrel A, Hartmann A. Cicatrization of wounds I. The relation between the size of a wound and the rate of its cicatrization. J Exp Med. 1916;24(5):429-50. 
154. Wells RG. The role of matrix stiffness in regulating cell behavior. Hepatology. 2008;47(4):1394-400.

155. Wells RG. Tissue mechanics and fibrosis. Biochim Biophys Acta (BBA) - Mol Basis Dis. 2013;1832(7):884-90.

156. Caliari SR, Perepelyuk M, Cosgrove BD, Tsai SJ, Lee GY, Mauck $\mathrm{RL}$, et al. Stiffening hydrogels for investigating the dynamics of hepatic stellate cell mechanotransduction during myofibroblast activation. Sci Rep. 2016;6(1):21387.

157. Görtzen J, Schierwagen R, Bierwolf J, Klein S, Uschner FE, van der Ven PF, et al. Interplay of matrix stiffness and c-SRC in hepatic fibrosis. Front Physiol. 2015;6:359 This study investigates the interaction of c-SRC and RhoA under different matrix stiffness conditions.

158. Hemmann S, Graf J, Roderfeld M, Roeb E. Expression of MMPs and TIMPs in liver fibrosis - a systematic review with special emphasis on anti-fibrotic strategies. J Hepatol. 2007;46(5):95575.

159. Martinez-Hernandez A, Amenta PS. The extracellular matrix in hepatic regeneration. FASEB J. 1995;9(14):1401-10.

160. Campana L, Iredale JP. Regression of liver fibrosis. Semin Liver Dis. 2017;58(1):1-10.

161. Kessenbrock K, Plaks V, Werb Z. Matrix metalloproteinases: regulators of the tumor microenvironment. Cell. 2010;141(1):52-67.

162. Moreira RK. Hepatic stellate cells and liver fibrosis. Arch Pathol Lab Med. 2007;131(11):1728-34.

163. Benyon RC, Hovell CJ, Da Gaça M, Jones EH, Iredale JP, Arthur MJ. Progelatinase A is produced and activated by rat hepatic stellate cells and promotes their proliferation. Hepatology. 1999;30(4):977-86.

164. Anders H-J, Schaefer L. Beyond tissue injury - damage-associated molecular patterns, toll-like receptors, and inflammasomes also drive regeneration and fibrosis. J Am Soc Nephrol. 2014;25(7): $1387-400$.

165. Iozzo RV, Schaefer L. Proteoglycan form and function: a comprehensive nomenclature of proteoglycans. Matrix Biol. 2015;42:11-55.

166. Schaefer L. Complexity of danger: the diverse nature of damageassociated molecular patterns. J Biol Chem. 2014;289(51):35237-45.

167. Moreth K, Iozzo RV, Schaefer L. Small leucine-rich proteoglycans orchestrate receptor crosstalk during inflammation. Cell Cycle. 2012;11(11):2084-91.

168. Piccinini AM, Midwood KS. DAMPening inflammation by modulating TLR signalling. Mediators Inflamm [Internet]. 2010;2010: 672395. Available from: https://www.ncbi.nlm.nih.gov/pmc/articles/ PMC2913853/. Accessed 11 Jan 2021.

169. Frey H, Schroeder N, Manon-Jensen T, Iozzo RV, Schaefer L. Biological interplay between proteoglycans and their innate immune receptors in inflammation. FEBS J. 2013;280(10):2165-79.
170. Schaefer L, Babelova A, Kiss E, Hausser H-J, Baliova M, Krzyzankova M, et al. The matrix component biglycan is proinflammatory and signals through Toll-like receptors 4 and 2 in macrophages. J Clin Invest. 2005;115(8):2223-33.

171. Nastase MV, Young MF, Schaefer L. Biglycan. J Histochem Cytochem. 2012;60(12):963-75.

172. Hsieh LT-H, Nastase M-V, Zeng-Brouwers J, Iozzo RV, Schaefer L. Soluble biglycan as a biomarker of inflammatory renal diseases. Int J Biochem Cell Biol. 2014;54:223-35.

173. Merline R, Moreth K, Beckmann J, Nastase MV, Zeng-Brouwers J, Tralhão JG, et al. Signaling by the matrix proteoglycan decorin controls inflammation and cancer through PDCD4 and MicroRNA-21. Sci Signal. 2011;4(199):ra75.

174. Gruber E, Heyward C, Cameron J, Leifer C. Toll-like receptor signaling in macrophages is regulated by extracellular substrate stiffness and Rho-associated coiled-coil kinase (ROCK1/2). Int Immunol. 2018;30(6):267-78.

175. Lo C-M, Wang H-B, Dembo M, Wang Y. Cell movement is guided by the rigidity of the substrate. Biophys J. 2000;79(1): 144-52.

176. Riveline D, Zamir E, Balaban NQ, Schwarz US, Ishizaki T, Narumiya S, et al. Focal contacts as mechanosensors. J Cell Biol. 2001;153(6): 1175-86.

177. del Rio A, Perez-Jimenez R, Liu R, Roca-Cusachs P, Fernandez JM, Sheetz MP. Stretching single talin rod molecules activates vinculin binding. Science. 2009;323(5914):638-41.

178. Chan CE, Odde DJ. Traction dynamics of filopodia on compliant substrates. Science. 2008;322(5908):1687-91.

179. Elosegui-Artola A, Trepat X, Roca-Cusachs P. Control of mechanotransduction by molecular clutch dynamics. Trends Cell Biol. 2018;28(5):356-67.

180. Elosegui-Artola A, Oria R, Chen Y, Kosmalska A, PérezGonzález C, Castro N, et al. Mechanical regulation of a molecular clutch defines force transmission and transduction in response to matrix rigidity. Nat Cell Biol. 2016;18(5):540-8 This study investigates the influence of matrix stiffness on cell function.

181. Sunyer R, Conte V, Escribano J, Elosegui-Artola A, Labernadie A, Valon L, et al. Collective cell durotaxis emerges from longrange intercellular force transmission. Science. 2016;353(6304): $1157-61$.

Publisher's Note Springer Nature remains neutral with regard to jurisdictional claims in published maps and institutional affiliations. 